\title{
ANÁLISE ESPAÇO-TEMPORAL DA COBERTURA VEGETAL NA ÁREA DE PROTEÇÃO AMBIENTAL DO CARIRI, PARAÍBA, BRASIL
}

\author{
ANALYSIS OF THE SPATIAL AND TEMPORAL VARIATIONS \\ OF VEGETATION COVER IN THE ENVIRONMENTAL \\ PROTECTION AREA OF CARIRI, PARAÍBA, BRAZIL
}

\begin{abstract}
ANÁLISIS ESPACIO-TEMPORAL DE LA COBERTURA VEGETAL EN EL ÁREA DE PROTECCIÓN AMBIENTAL DEL CARIRI, PARAÍBA, BRASIL

Lorena Andrea Cortes Ballén - Universidade Federal da Paraíba - Paraíba - João Pessoa - Brasil lorean12@gmail.com
\end{abstract}

Bartolomeu Israel de Souza - Universidade Federal da Paraíba - Paraíba - João Pessoa - Brasil

bartolomeuisrael@gmail.com

Eduardo Rodrigues Viana de Lima - Universidade Federal da Paraíba - Paraíba - João Pessoa - Brasil
eduvianalima@gmail.com

\section{Resumo}

A Caatinga está inserida na região semiárida do Nordeste e caracteriza-se por floras adaptadas que vivem com a semiaridez e o ritmo sazonário do clima e da hidrologia. Apresenta uma longa história de uso e ocupação que tem transformado consideravelmente as coberturas de vegetação natural que ocorrem neste bioma. $\mathrm{Na}$ atualidade, com a disponibilidade das tecnologias de sensoriamento remoto é possível avaliar as mudanças espaço-temporais nas diversas paisagens por meio da modelagem de vários parâmetros biofísicos da vegetação. 0 presente estudo teve como objetivo analisar as mudanças espaço-temporais da cobertura vegetal na Área de Proteção Ambiental (APA) do Cariri por meio dos índices NDVI e SAVI a partir do processamento de imagens do sensor TM Landsat 5 dos anos 1989, 2005 e 2010. Seis classes de cobertura foram encontradas na APA, sendo quatro delas correspondentes com as fitofisionomias de Caatingas com maior e menor nível de antropização. Os resultados mostram um declínio progressivo das Caatingas mais densas no período analisado. 0 NDVI teve uma resposta mais próxima às condições reais da vegetação da área de estudo. 0 s índices de vegetação analisados representam um indicador da qualidade ambiental da área para um futuro planejamento ambiental.

Palavras-chave: Caatinga, sensoriamento remoto, índices de vegetação.

\section{Abstract}

The Caatinga is inserted in the semiarid region of the Northeast and is characterized by floras adapted to live with semi-arid and seasonal rhythm of climate and hydrology. It has a long history of use and occupation that has considerably changed the natural vegetation covers that occur in this biome. Currently, with the availability of remote sensing technologies it is possible to evaluate the spatial and temporal changes in the various landscapes through the modeling of various biophysical parameters of vegetation. This study aimed to analyze the spatial and temporal changes of vegetation cover in the Cariri Área de Proteção Ambiental (APA) through NDVI and SAVI indexes with the processing of TM Landsat 5 sensor images during the years 1989, 2005 and 2010. Six cover classes were found in the APA, being four of them corresponding to the vegetation types of Caatingas with higher and lower level of human disturbance. The results show a progressive decline 
of the densest Caatingas in the analyzed period. The NDVI was closer to the real conditions of the vegetation of the study area. The vegetation indexes analyzed represent an indicator of the environmental quality of the area for future environmental planning.

Keywords: Caatinga, remote sensing, vegetation indexes.

\section{Resumen}

La Caatinga se sitúa en la región semiárida del Nordeste y se caracteriza por las floras adaptadas que viven bien en regiones semiáridas y en el ritmo estacional del clima y de la hidrología. Presenta una larga historia de uso y ocupación que transformó considerablemente las coberturas de vegetación natural que se producen en ese bioma. Actualmente, con la disponibilidad de tecnologías de teledetección, es posible evaluar los cambios espacio-temporales en los distintos paisajes a través del modelado de varios parámetros biofísicos de la vegetación. Este estudio tuvo como objetivo analizar los cambios espacio-temporales de las coberturas de vegetación en el Área de Proteção Ambiental (APA) del Cariri, por medio de los índices NDVI y SAVI mediante el procesamiento de imágenes de la teledetecciónTM Landsat 5 de los años 1989, 2005 y 2010. Seis clases de cobertura fueron encontradas en el APA, cuatro de ellas corresponden a los tipos de vegetación de Caatingas con mayor o menor nivel de intervención antrópica. Los resultados muestran un retroceso progresivo de las Caatingas más densas en el período analizado. El NDVI tuvo una respuesta más cercana a las condiciones reales de la vegetación del área de estudio. Los índices de vegetación analizados representan un indicador de la calidad ambiental de la zona para una futura planificación ambiental.

Palabras clave: Caatinga, teledetección, índices de vegetación.

Introdução

O bioma Caatinga está inserido na região semiárida do Nordeste e envolve os Estados do Ceará, Rio Grande do Norte, Paraíba, Pernambuco, Alagoas, Sergipe, o sudoeste do Piauí, partes do interior da Bahia e do norte de Minas Gerais, no Vale do Jequitinhonha (IBGE, 2004).

Nas Caatingas ocorrem floras adaptadas que vivem com a semiaridez e o ritmo sazonário do clima e da hidrologia (Fernandes, 2000). Fitofisionomicamente, as caatingas podem ser caracterizadas como florestas arbóreas ou arbustivas, compreendendo principalmente árvores e arbustos baixos sem formar um dossel contínuo, muitos dos quais apresentam espinhos, microfilia e algumas características xerofíticas. Cactos e bromélias terrestres são, também, elementos importantes da sua paisagem. O estrato herbáceo é efêmero e constituído principalmente por terófitas e geófitas que aparecem apenas na curta estação chuvosa (Leal; Tabarelli; Silva, 2003; Queiroz, 2006).

De acordo com o Relatório de Monitoramento do Desmatamento na Caatinga (MMA, 2010), 45,4\% da área total do bioma está alterada, fato que o coloca entre os biomas brasileiros mais modificados pelo homem, superado apenas pela Mata Atlântica e pelo Cerrado (Castelletti et al., 2003). Segundo o Ministério do Meio Ambiente (Brasil, 2011), a principal 
causa da destruição da Caatinga se deve ao desmatamento da vegetação nativa, que é convertida em lenha e carvão vegetal. Além disso, a pecuária extensiva e os sistemas agrícolas nas áreas mais férteis ocasionam a devastação da Caatinga (Santana; Souto, 2006).

Uma das estratégias governamentais para proteger a diversidade biológica, planejar o processo de ocupação e assegurar a sustentabilidade do uso dos recursos naturais, são as unidades de conservação, estruturadas dentro do Sistema Nacional de Unidades de Conservação da Natureza (SNUC), estabelecido através da aprovação da Lei no 9.985 de 2000. Apenas 8,4\% de seu território esta protegido em unidades de conservação federais e estaduais, sendo apenas 1,4\% de proteção integral enquanto a maior parte e as maiores unidades são de uso sustentável (Hauff, 2010). Essa situação expõe o grau de fragilidade das Caatingas no país e a extrema necessidade de estudar ainda mais as transformações das paisagens deste bioma e estabelecer estratégias que assegurem a qualidade de sua viabilidade no tempo.

O monitoramento das modificações efetuadas nas paisagens pode ser acompanhado por meio de técnicas de sensoriamento remoto (Ponzoni; Shimabukuro; Kuplich, 2012). Tecnicamente, os parâmetros biofísicos da vegetação podem ser modelados através dos índices de vegetação, que são transformações lineares de bandas espectrais nas faixas do vermelho (V) e no infravermelho próximo (IVP) do espectro electromagnético (Baret et al., 1989). Esses índices são medidas radiométricas adimensionais que identificam a abundância relativa e a atividade da vegetação verde (Baret et al., 1989). Dentre os índices de vegetação mais frequentemente utilizados, se destacam: o Índice de Vegetação por Diferença Normalizada (NDVI), o Índice de Vegetação Ajustado ao Efeito do Solo (SAVI) e o Índice de Área Foliar (IAF) (Rouse et al., 1973).

A Área de Proteção Ambiental (APA) do Cariri foi criada pela Secretaria de Meio Ambiente do Estado da Paraíba mediante o Decreto Estadual 25.083 de 8 de junho de 2004. Atualmente essa unidade conservação não apresenta nenhum estudo de base científica que identifique os recursos naturais que nela se encontram, carecendo também de um plano de manejo ambiental que permita planejar a ocupação do uso do solo e assim garantir a conservação dos recursos naturais. Devido a esta situação, urge que sejam desenvolvidos estudos que caracterizem, avaliem e monitorem as condições ambientais dos ecossistemas desta área, pelo que o objetivo deste estudo foi realizar uma análise espaço-temporal das mudanças da cobertura vegetal na área, subsidiada pela geração dos 
índices de vegetação NDVI e SAVI, comumente usados para analisar padrões biofísicos da vegetação da Caatinga.

\section{Área de estudo}

A APA do Cariri abrange uma extensão de 18.560 hectares e envolve os municípios de Boa Vista, Cabaceiras e São João do Cariri, no Estado da Paraíba. A drenagem principal da área encontra-se representada pelos rios Soledade, Boa Vista e Taperoá (Figura 1).

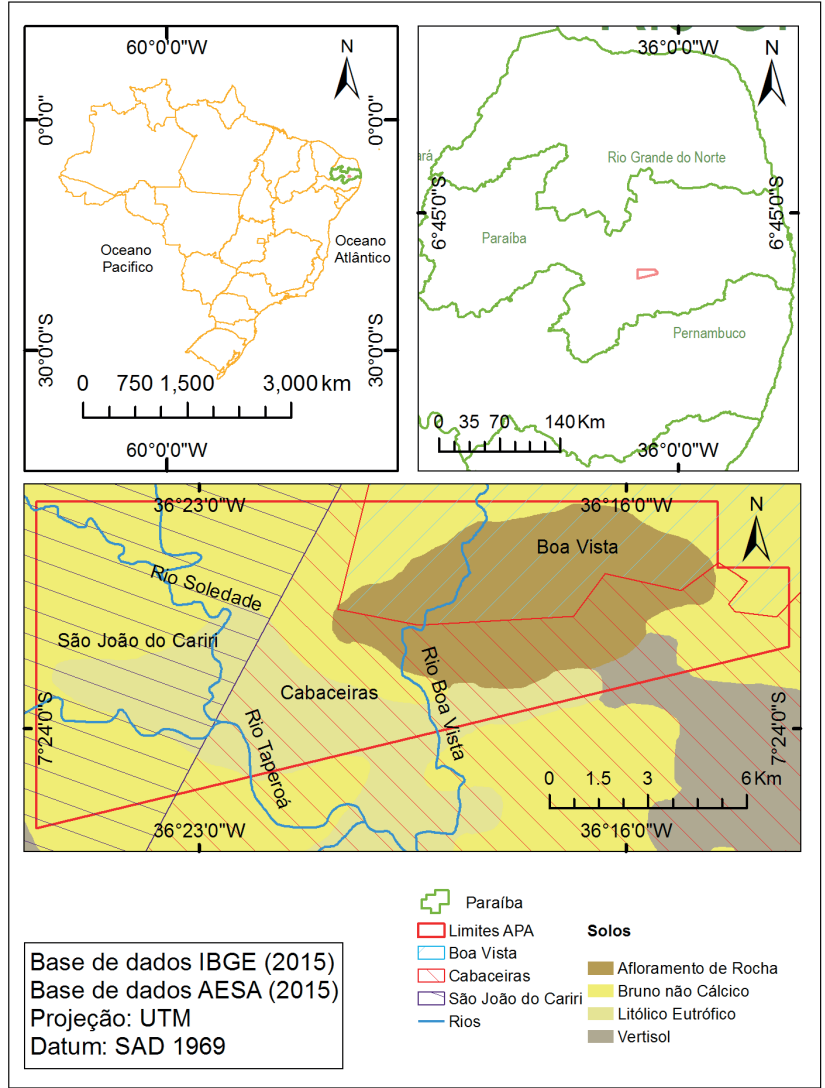

Figura 1 - Mapa de localização da APA do Cariri - PB

Fonte: Elaborado por Lorena Cortes (2015). 
O Cariri é uma microrregião do estado da Paraíba localizada na franja ocidental do planalto da Borborema. É composta por 29 municípios e ocupa uma área de $11.233 \mathrm{~km}^{2}$ (Alves, 2009). Encontra-se em plena "diagonal seca", onde se apresentam os menores índices de precipitação do semiárido brasileiro (Cohen; Duqué, 2001). Na área da APA se apresenta uma precipitação média anual entre 400 e 500 mm (AESA, 2015), com um clima semiárido (BSh), segundo Köppen (1931), e temperaturas médias anuais entre $25^{\circ} \mathrm{C}$ e $27^{\circ} \mathrm{C}$.

A APA encontra-se na Província Borborema onde predominam as rochas do Pré-cambriano, particularmente o calcário cristalino, as rochas gabróides e as rochas granitoides. Os tipos de solos identificados nesta área são o Neossolo Regolitico, o Neossolo Litólico, o Luvisolo Crômico e, nas várzeas, o Neossolo Flúvico (EMBRAPA, 2006).

O bioma dominante na APA é a Caatinga, vegetação que se caracteriza por uma fisionomia e composição florística variável em função do tipo de solo e da pluviosidade. Dominam espécies caducifólias de caráter xerófilo e grande quantidade de plantas espinhosas. Fitofisionomicamente as caatingas podem ser caracterizadas como florestas arbóreas ou arbustivas, compreendendo principalmente árvores e arbustos baixos sem formar um dossel contínuo. Cactos e bromélias terrestres são, também, elementos importantes da sua paisagem. O estrato herbáceo é efêmero e constituído principalmente por terófitas e geófitas que aparecem apenas na curta estação chuvosa (Leal; Tabarelli; Silva, 2003; Queiroz, 2006).

\section{Metodologia}

Foram utilizadas três imagens do Sensor TM Landsat 5 do Instituto Nacional de Pesquisas Espaciais (INPE), correspondendo às datas de 02/08/1989, 29/07/2005 e 22/04/2010, com ponto e órbita de 215/65 e resolução espacial de $30 \mathrm{~m}$.

Foram feitas várias saídas de campo durante os anos de 2014 e 2015 para realizar um reconhecimento da área de estudo e do tipo de cobertura vegetal presente. As coberturas foram validadas em campo por meio de 20 pontos, localizados de acordo com uma classificação prévia da vegetação na imagem de satélite mais recente.

Todas as imagens processadas foram georreferenciadas com datum WGS 1984_UTM, no Software ArcGIS (ArcInfo) 10.1, desenvolvido pela ESRI. 
O processamento das imagens contemplou os seguintes tipos de procedimentos: reconhecimento prévio; correção geométrica; identificação das bandas 3 e 4; delimitação da área de estudos segundo o shape de limites oficiais da APA do Cariri; geração dos índices de vegetação NDVI e SAVI; definição, caracterização e validação das classes; classificação e avaliação dos resultados por meio de uma análise qualitativa e quantitativa de dados e finalmente uma elaboração do diagnóstico final das coberturas vegetais na APA.

\section{- Índices de vegetação}

Para gerar os índices de vegetação foi preciso realizar os seguintes procedimentos:

Realizou-se o cálculo da radiância espectral de cada banda (L $\lambda \mathrm{i}$ ), ou seja, a calibração radiométrica, em que o número digital (ND) de cada pixel da imagem é convertido em radiância espectral da seguinte forma, de acordo com Markham e Baker (1987):

$$
\mathrm{L}_{\lambda \mathrm{i}}=\mathrm{a}_{\mathrm{i}}+\left(\frac{\mathrm{b}_{\mathrm{i}}-\mathrm{a}_{\mathrm{i}}}{255}\right) \mathrm{ND}
$$

onde a e b são as radiâncias espectrais mínima e máxima (W/m²/sr/ $/ \mu \mathrm{m})$, ND é a intensidade do pixel (0 a 255); e i corresponde as bandas do Sensor TM Landsat.

O cálculo da reflectância planetária monocromática de cada banda ( $\rho) ~ \lambda i$, foi definida como a razão entre o fluxo da radiação solar refletido e o fluxo da radiação solar incidente, por meio da seguinte fórmula:

$$
\rho_{\lambda \mathrm{i}}=\frac{\pi \cdot \mathrm{L}_{\lambda \mathrm{i}}}{\mathrm{k}_{\lambda \mathrm{i}} \cdot \cos Z \cdot \mathrm{d}_{\mathrm{r}}}
$$

onde $\lambda \mathrm{i} L$ é a radiância espectral de cada banda, $\lambda \mathrm{i}$ k é a irradiância solar espectral de cada banda no topo da atmosfera $\left(\mathrm{W} / \mathrm{m}^{2} / \mathrm{mm}\right)$, Z é o ângulo zenital solar e d $\mathrm{r}_{\mathrm{r}}$ o quadrado da razão entre a distância média Terra-Sol (ro) e a distância Terra-Sol (r) em dado dia do ano (DSA), que segundo Iqbal (1983), é obtida pela seguinte equação:

$$
d_{r}=1+0.033 \cos (\text { DSA. } 2 \pi / 365)
$$


Índice de Vegetação da Diferença Normalizada (NDVI): tenta minimizar os efeitos topográficos ao produzir uma escala linear de medida. Seu valor pode variar entre -1 e +1 (quanto mais próximo de +1 , maior a densidade de cobertura vegetal). $\mathrm{O} 0$ representa valor aproximado para ausência de vegetação (Ponzoni; Shimabukuro; Kuplich, 2012):

$$
\mathrm{NDVI}=\frac{\mathrm{IVP}-\mathrm{V}}{\mathrm{IVP}+\mathrm{V}}
$$

Índice de Vegetação ajustado ao solo (SAVI): é uma medida de adaptação do NDVI, com o intuito de minimizar os efeitos do solo de fundo no sinal da vegetação ao incorporar uma constante de ajuste de solo, identificada como o fator L na equação do NDVI (Huete, 1988). Para esta análise foi aplicado um fator de ajuste de $\mathrm{L}=0,5$ valor que representa uma vegetação com densidade intermediária:

$$
\text { SAVI }=\frac{(1+L)\left(\rho_{\mathrm{IV}}-\rho_{\mathrm{V}}\right)}{\left(\mathrm{L}+\rho_{\mathrm{IV}}+\rho_{\mathrm{V}}\right)}
$$

Com os resultados obtidos, foi feita uma classificação dos intervalos de acordo com os tipos de cobertura. Embora exista uma classificação oficial para a Caatinga (IBGE, 2012), a nomenclatura utilizada no presente trabalho teve o objetivo de efetuar o mapeamento das fitofisionomias encontradas na área estudada. Para tanto, tomou-se por base a classificação adotada por Souza (2008) relacionada com o reconhecimento dos tipos de Caatinga existente no Cariri, onde principalmente a vegetação se distingue por um alto e baixo nível de antropização e degradação. Dessa forma, os intervalos estabelecidos foram: <0 Corpos de Água, 0 a 0,2 Solo Exposto; 0,2 a 0,4 Caatinga Arbustiva-Aberta; 0,4 a 0,5 Caatinga Arbustiva-Semiaberta; 0,5 a 0,6 Caatinga Arbustiva-Fechada e >0,60 Caatinga Arbustiva Arbórea-Fechada.

\section{Resultados}

Os resultados dos índices de vegetação NDVI e SAVI apresentaram várias diferenças de valores nos três recortes temporais. Embora os valores médios sejam muito próximos, com exceção do SAVI para o ano 2010, que apresentou um valor médio de 0.29 , o desvio padrão indicou um grau 
de variação maior dos dados em relação ao valor médio para o NDVI. Os valores máximos encontrados nos dois índices são muito próximos, situação que não aconteceu com os valores mínimos que apresentaram grandes variações (Quadro 1).

Quadro 1 - Valores encontrados para o NDVI e o SAVI.

\begin{tabular}{|c|c|c|c|c|c|}
\hline \multirow{2}{*}{ Ano } & $\begin{array}{c}\text { Índices de } \\
\text { vegetação }\end{array}$ & $\begin{array}{c}\text { Valores } \\
\text { mínimos }\end{array}$ & $\begin{array}{c}\text { Valores } \\
\text { máximos }\end{array}$ & Valor médio & Desvio padrão \\
\hline \multirow{2}{*}{1989} & SAVI & $-0,43$ & 0,76 & 0,47 & 0,089 \\
\cline { 2 - 6 } & NDVI & $-0,93$ & 0,76 & 0,42 & 0,133 \\
\hline \multirow{2}{*}{2005} & SAVI & $-0,35$ & 0,76 & 0,42 & 0,086 \\
\cline { 2 - 6 } & NDVI & $-0,79$ & 0,79 & 0,41 & 0,113 \\
\hline \multirow{2}{*}{2010} & SAVI & $-0,3$ & 0,61 & 0,29 & 0,071 \\
\cline { 2 - 6 } & NDVI & $-0,6$ & 0,76 & 0,41 & 0,134 \\
\hline
\end{tabular}

Fonte: Elaborado por Lorena Cortes (2015).

O SAVI para o ano 1989 encontrou a representação das seis classes estabelecidas, apresentando uma maior cobertura em área as classes de Caatinga Arbustiva-Semiaberta, Caatinga Arbustiva-Fechada e Caatinga Arbustiva-Aberta. No ano 2005 foram identificadas seis classes. As classes com maior cobertura em área foram a Caatinga Arbustiva-Semiaberta, Caatinga Arbustiva-Aberta e Caatinga Arbustiva-Fechada. Observou-se que as coberturas com mais densidade diminuíram e aparecem melhor representadas na parte oeste da APA. A zona dos afloramentos rochosos (lajedos), localizados na porção leste da área de estudo, apresentou uma variação no comportamento espectral, dada pela presença de nuvens que ficaram justo nessa área. Para o ano 2010, encontraram-se cinco classes. A maior cobertura em área foi da Caatinga Arbustiva-Semiaberta e da Caatinga Arbustiva-Aberta (Quadro 2).

Quadro 2 - Valores encontrados no SAVI para o ano 2010 na APA do Cariri

\begin{tabular}{|c|c|c|}
\hline Classe & Área(km $\left.{ }^{2}\right)$ & Percentual de Abrangência \\
\hline Água & 0.12 & 0.08 \\
\hline Solo Exposto & 8.24 & 5.22 \\
\hline Caatinga Arbustiva-Aberta & 64.59 & 40.96 \\
\hline Caatinga Arbustiva-Semiaberta & 73.23 & 46.43 \\
\hline Caatinga Arbustiva-Fechada & 11.53 & 7.31 \\
\hline
\end{tabular}


As classes mais densas diminuíram ao ponto que a Caatinga Arbustiva Arbórea-Fechada desaparece e a Caatinga Arbustiva-Fechada aparece representada por duas manchas localizadas nas porções oeste e norte da área estudada e por pequenas manchas em torno dos lajedos (Figura 2).

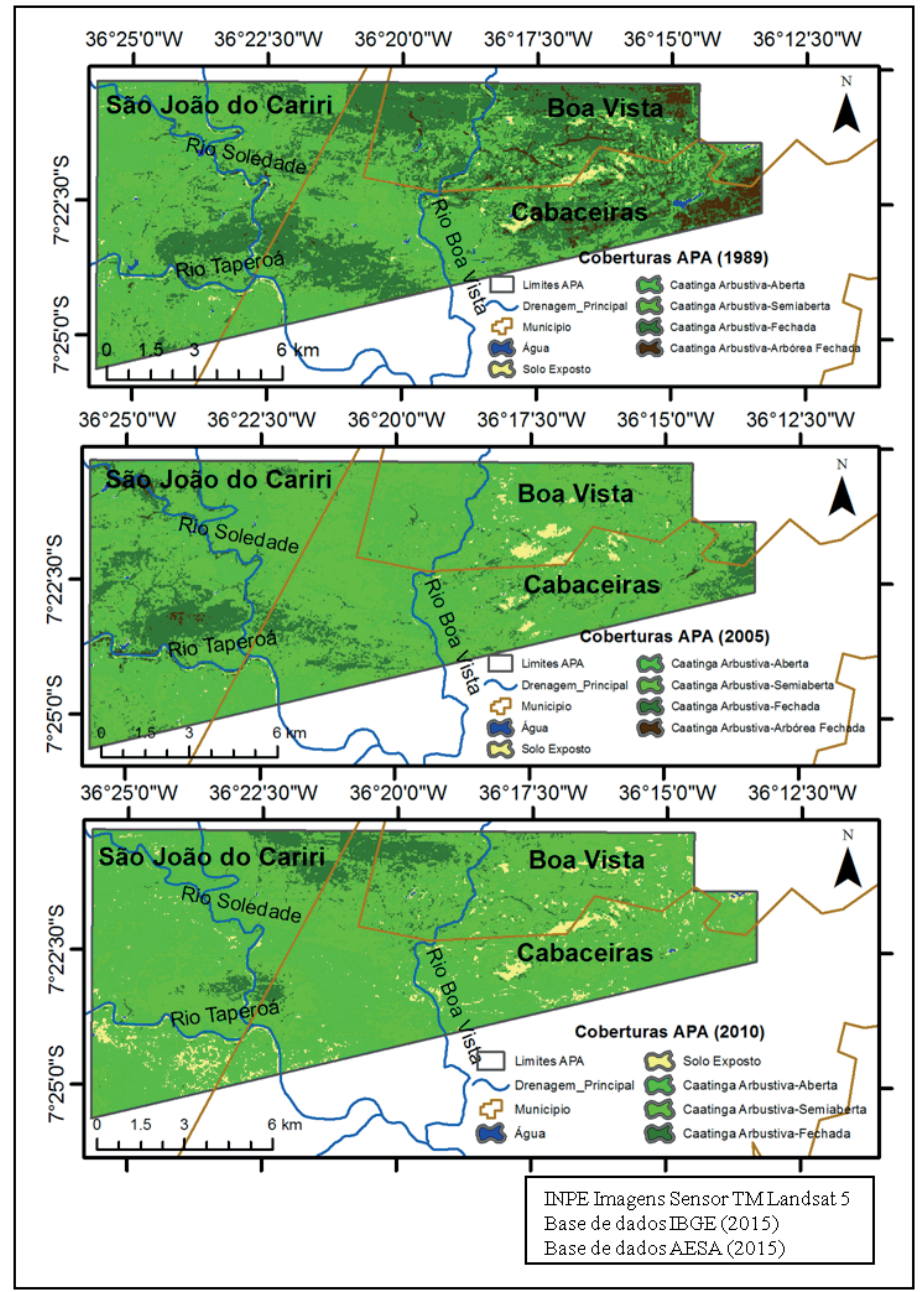

Figura 2 - Mapas temáticos da vegetação identificada pelo SAVI para os anos 1989, 2005 e 2010 na APA do Cariri.

Fonte: Elaborado por Lorena Cortes (2015). 
O NDVI para o ano 1989 apresentou seis classes, com maior cobertura para as Caatingas Arbustiva-Semiaberta, Arbustiva-Aberta e ArbustivaFechada. A classe de cobertura mais densa, a Caatinga Arbustiva ArbóreaFechada, aparece representada na APA especialmente na porção leste, no entorno dos lajedos e em algumas outras pequenas manchas. A classe Solo Exposto, associado ao intervalo de 0 a 0,2, pode ter apresentando interferência de dados, uma vez que no NDVI este intervalo começou com valores negativos que são atribuídos a corpos hídricos. Este fato poder ser corroborado com o desvio padrão que foi maior para este índice.

Para o ano 2005 o NDVI apresentou seis classes, com maior cobertura em área para as classes Caatinga Arbustiva-Semiaberta, Caatinga Arbustiva-Aberta e Caatinga Arbustiva-Fechada. As Caatingas com maior nível de antropismo tiveram uma considerável expressão na paisagem da APA. Destaca-se, entretanto, que a zona de maior expressão dos lajedos teve interferência de visualização, devido à presença de nuvens na imagem de satélite utilizada para este ano. Evidencia-se na porção nordeste da APA uma maior exposição de solo devido ao estabelecimento de uma empresa de agroindústria que foi identificada em campo como a Companhia de Alimentos do Nordeste - Cialne, empresa de avicultura e pecuária.

Os valores encontrados do NDVI no ano 2010 mostraram a presença de seis classes, com uma maior distribuição em área para Caatinga Arbustiva-Semiaberta, Caatinga Arbustiva-Aberta e Caatinga e ArbustivaFechada (Tabela 1).

Tabela 1 - Valores encontrados no NDVI para o ano 2010 na APA do Cariri

\begin{tabular}{|c|c|c|}
\hline Classe & Área(km²) & Percentual de Abrangência \\
\hline Água & 0.4959 & 0.31 \\
\hline Solo Exposto & 22.2255 & 14.1 \\
\hline Caatinga Arbustiva-Aberta & 45.4788 & 28.85 \\
\hline Caatinga Arbustiva-Semiaberta & 54.0054 & 34.26 \\
\hline Caatinga Arbustiva-Fechada & 28.7505 & 18.24 \\
\hline Caatinga Arbustivo-Arbórea Fechada & 6.6906 & 4.24 \\
\hline
\end{tabular}

Fonte: Elaborado por Lorena Cortes (2015)

As classes de Caatinga mais densas se localizaram nas porções norte, oeste e no entorno dos lajedos. As Caatingas com mais antropismo foram dominantes na paisagem da APA. A porção leste da Unidade de 
Conservação apresentou uma zona de maior exposição do solo que foi identificada em campo como uma das maiores área de extração mineral da indústria Bentonit União Nordeste S/A, que retira em grande escala o minério bentonita (Figura 3).

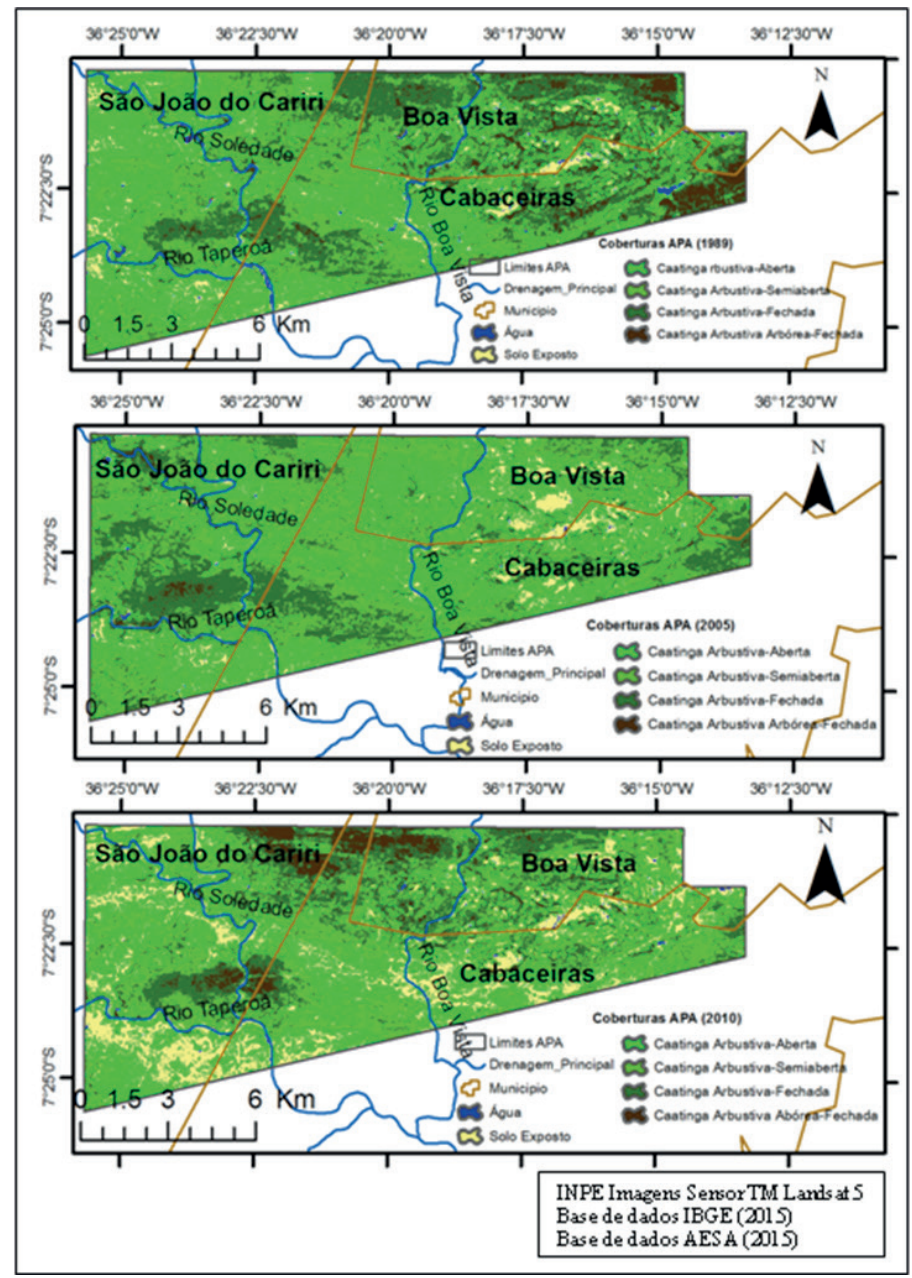

Figura 3 - Mapas temáticos da vegetação identificada pelo NDVI para os anos 1989, 2005 e 2010 na APA do Cariri

Fonte: Elaborado por Lorena Cortes (2015). 


\section{Discussão}

A perda de cobertura de Caatingas mais densas ao longo do tempo é o reflexo da história da ocupação do Cariri e das formas como ela se processou. As consequências dos impactos ambientais negativos das atividades humanas como fogo, a pecuária extensiva, o sistema agrícola e extrativismo vegetal terminou gerando mudanças acentuadas nas paisagens (Alves, 2007; Nascimento; Alves, 2008).

Na década de 1980 a pecuária volta a ser a atividade econômica dominante no Cariri. Existe assim um aumento do rebanho e da pressão sobre a vegetação, principalmente o caprino, que devido a seus hábitos alimentares transformaram a herbivoria numa característica comum nestas terras. Além disso, existe a introdução de espécies exóticas que são utilizadas como alimento para o gado, como a algaroba (Prosopis juliflora), e secundariamente o capim-buffel (Centhrus ciliaris) que, junto com a palma forrageira (Opontus fícus indica) de introdução mais antiga, passaram a dominar espaços ocupados pelos diversos tipos de caatinga (Souza, 2008). Esta condição foi uma constante em toda a área da APA. Na porção norte dessa área, onde se conseguiu evidenciar Caatingas mais densas, também foi possível identificar em campo grandes áreas dominadas pela algaroba, o que interfere diretamente nas respostas espectrais da vegetação típica de caatinga (Figura 4).

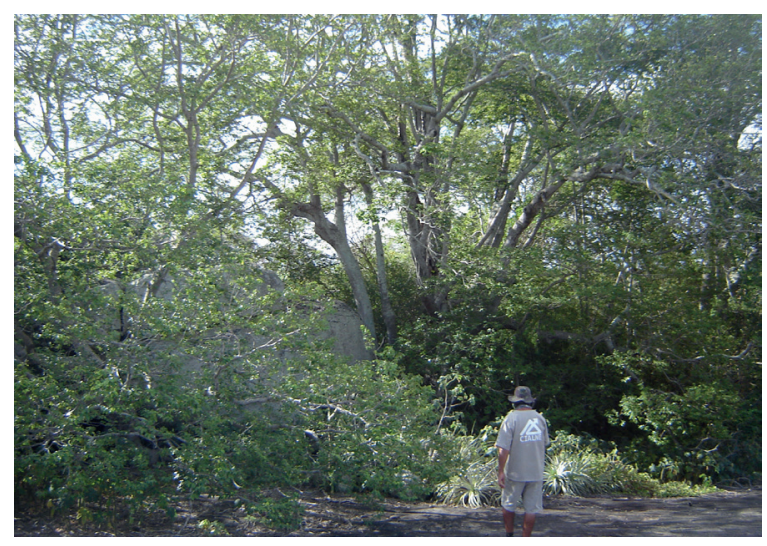

Figura 4 - Cobertura de Caatinga arbórea na APA do Cariri Fonte: Elaborado por Lorena Cortes (2015) 
As áreas próximas às várzeas dos rios tiveram uma tendência a uma maior exploração, principalmente pela presença de água no lençol freático. Nestas zonas foram desenvolvidas lavouras de ciclo curto como o milho e o feijão, principalmente para subsistência. (Souza, 2008). Outra cultura desenvolvida nestas zonas foi o algodão, cultivo que se espalhou no semiárido no século XVIII por ser uma cultura resistente aos períodos anuais de estiagem (Silva, 2003).

O aumento gradativo da cobertura das Caatingas com mais antropismo durante o período de tempo analisado, embora exista o estabelecimento oficial de uma Área de Proteção Ambiental desde o ano 2004, nos leva a concluir que isto não tem repercutido positivamente na proteção dos recursos naturais presentes nessa APA. Esta condição é muito mais evidente no ultimo recorte temporal analisado onde a porção leste da Unidade de Conservação apresenta uma zona de maior exposição do solo no NDVI e maior presença de caatinga arbustiva aberta no SAVI, o que coincide com o identificado em campo, havendo nesta zona uma das maiores área de extração mineral da indústria Bentonit União Nordeste S/A (Figura 5).
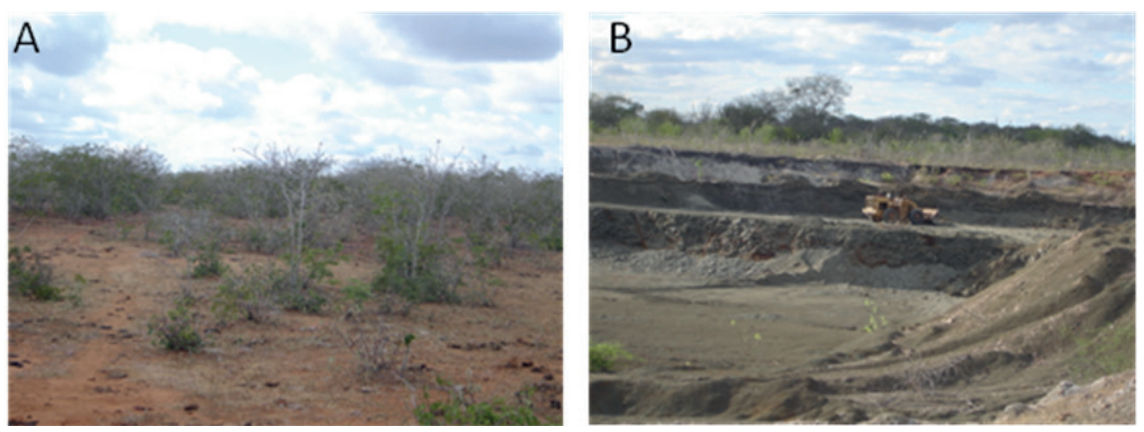

Figura 5 - A. Cobertura de Caatinga aberta, B. Zona de exploração mineira na APA do Cariri Fonte: Elaborado por Lorena Cortes (2015)

Os resultados dos índices de vegetação estimados devem ser interpretados de forma conjunta, uma vez que as respostas espectrais do índice SAVI podem estar superestimando coberturas de Caatingas com mais antropismos que se expressam no NDVI, como o solo exposto. No entanto, este estudo considera que o NDVI respondeu de uma forma satisfatória 
com as condições encontradas no reconhecimento de coberturas feito em campo. Vale a pena ressaltar, que a variável clima, em particular a situação de chuva/seca, sempre será uma constante que determina de forma significativa a resposta da vegetação de Caatinga.

Na área de estudo, o NDVI e o SAVI expressaram de forma satisfatória os impactos de uma história de uso e ocupação do solo de uma região sem nenhum tipo de planejamento ambiental do território, que repercutiu significativamente na degradação da vegetação de porte mais denso. Resultados semelhantes foram encontrados por diversos autores desenvolvidos na mesma região analisada neste trabalho, dentre os quais destacamos entre os mais recentes Countinho et al., (2012) no município de São João do Cariri, Nascimento et al., (2014) na sub-bacia do alto Paraíba, Souza et al., (2015) em áreas dos municípios de Matureia, São João do Tigre; e Alves e Vieira (2015) que encontraram correlações negativas entre os índices de vegetação e a temperatura média do ar e correlações positivas significativas com a precipitação pluvial, evidenciando que esta variável climática condiciona o desenvolvimento da vegetação na região.

\section{Considerações finais}

A falta de planejamento no momento de criação de uma área protegida repercute diretamente nos objetivos de conservação, já que o sucesso desta está em incorporar alvos de sustentabilidade de recursos naturais no processo histórico econômico que caracteriza a área. As formas de exploração atualmente praticadas na área de estudo não atendem as exigências legais, particularmente numa área com característica de proteção como a APA do Cariri. É preciso uma gestão conjunta dos órgãos de administração e fiscalização ambiental, em consonância com as prefeituras envolvidas para avaliar o estado desta Unidade de Conservação e exigir o cumprimento legal na ocupação do solo, principalmente das atividades que mais tem impactado os recursos naturais da área.

O uso de índices de vegetação nas análises da evolução espaço-temporal das coberturas vegetais de uma área determinada oferece um importante indicador de qualidade ambiental para obter, de forma relativamente rápida, informações relevantes para determinar processos de sucessão, tipos de ocupação do solo e degradação. 


\section{Agradecimentos}

O trabalho apresentado teve o apoio do Ministério do Meio Ambiente/Fundo Nacional sobre Mudanças Climáticas, ao qual tecemos nossos agradecimentos, pelo financiamento do projeto "Desenvolvimento de capacidades técnicas e institucionais de parceiros locais em bacias hidrográficas para o desenvolvimento de estratégias para a conservação de ambientes naturais: Conhecendo as relações biofísicas e antrópicas para subsidiar uma convivência sustentável no Alto Curso do rio Paraíba - PB”, Edital 02/2014 - Serviços Ecossistêmicos.

\section{Referências}

AESA. Agência Executiva de Gestão das Águas do Estado da Paraíba. Geoportal. Shapefiles. Disponível em: <http://www.aesa.pb.gov.br/geoprocessamento/ geoportal/shapes.html>. Acesso em: 10 maio 2015.

ALVES, J. J. A. Geoecologia da caatinga no semi-árido do Nordeste brasileiro. CLIMEP: Climatologia e Estudos da Paisagem, Rio Claro, v. 2, n. 1, p. 58-71, 2007.

. Caatinga do Cariri Paraibano. Geonomos, v. 17, n. 1, p. 19-25, 2009.

.;ARAUJO, M. A.; NASCIMENTO, S. S. Degradação da Caatinga: uma investigação ecogeográfica. Caatinga, Mossoró, v. 22, n. 3, p. 126-135, 2009.

ALVES, T. L. B.; VIEIRA, P. A. Análise da variação espacial e temporal do Índice de Vegetação e sua relação com parâmetros climáticos na Bacia Hidrográfica do alto curso do rio Paraíba, Estado da Paraíba, Brasil. Boletim Goiano de Geografia (Online), Goiânia, v. 35, n. 3, p. 530-553, set./dez. 2015.

BARET, F. et al. A vegetation index which minimizes soil brightness effects on LAI and APAR estimation. In: CANADIAN SYMPOSIUM ON REMOTE SENSING AND IGARSS, 12., 1989, Vancouver, Anais... Vancouver: Canadian Remote Sensing Society/IEEE Geoscience and Remote Sensing Society/ International Union of Radio Science/Canada Centre for Remote Sensing, 1989. p. 1355-1358.

BRASIL. Ministério do Meio Ambiente. Monitoramento do desmatamento dos biomas Brasileiros por satélite: acordo de Cooperação Técnica MMA/IBAMA. Monitoramento do Bioma Caatinga 2002 a 2008. MMA: Brasília, 2011. 46 p.

CASTELLETTI, C. H. M. et al. Quanto ainda resta da Caatinga? Uma estimativa preliminar. In: LEAL, I. R.; TABARELLI, M.; SILVA, J. M. C. (Org.). Ecologia e conservação da caatinga. Recife: Ed. Universitária da UFPE, 2003. p. 719-734.

COHEN, M.; DUQUE, G. Le deux visages du Sertão: stratégies paysannes face aux sécheresses (Nordeste du Brésil). Paris: Éditions de L’IRD, 2001. 
COUNTINHO S. A. R. et al. Análise comparativa dos índices de vegetação NDVI e SAVI no município de São Domingos do Cariri-PB. REVISTA GEONORTE, Edição Especial, v. 2, n. 4, p. 1217-1229, 2012.

EMBRAPA. Sistema brasileiro de classificação de solos. 2. ed. Rio de Janeiro, 2006. $306 \mathrm{p}$.

FERNANDES, A. Fitogeografia Brasileira. 2. ed. Fortaleza: Multigraf, 2000.

HAUFF, S. N. Representatividade dos ecossistemas da Caatinga nas Áreas Prioritárias e Unidades de Conservação. Relatório ao PNUD - PROGRAMA DAS NAÇÕES UNIDAS PARA O DESENVOLVIMENTO PROJETO BRA/00/021: Sustentabilidade e repartição dos benefícios da biodiversidade, 2010. Disponível em: <file:///C:/Users/Periodicos/Downloads/representativconservcaat_shauff_ revisojoo_03__produto_final_203_completo.pdf $>$. Acesso em: 13 out. 2016.

HUETE, A.R. A soil-adjusted vegetation index. Remote sensing of environment, Elsevier Science Publishing Co., New York, USA. n. 25, p. 295-309, 1988.

IBGE. Manual técnico da vegetação brasileira. Manuais Técnicos em Geociências. 2.ed.. IBGE: Rio de Janeiro, 2012.

IBGE. Mapa de Biomas do Brasil, primeira aproximação. Rio de Janeiro: IBGE. 2004. Disponível em: <http://www.ibge.gov.br/home/>. Acesso em: 23 out. 2015.

IQBAL, M. An introduction to solar radiation. Canadá: Academic Press, 1983. $408 \mathrm{p}$.

JENSEN, J. R. Sensoriamento Remoto do Ambiente: uma Perspectiva em Recursos Terrestres. São José dos Campos, SP: Parêntese, p. 604. 2009.

KÖPPEN, W. Grundriss der Klimakunde (Outline of climate science). Berlin: Walter de Gruyter, 1931. 388 p.

LEAL, R. I.; TABARELLI, M.; SILVA, J. M. C. do. Ecologia e conservação da caatinga. Recife: Ed. Universitária da UFPE, 2003.

MARKHAM, B. L.; BARKER, J. L. Thematic mapper band pass solar exoatmospherical irradiances. International Journal of Remote Sensing, v. 8, n. 3, p. 517-523, 1987.

NASCIMENTO, S. S.; ALVES, J. J. A. Um alerta ambiental do grau da desertificação no Estado da Paraíba. Encontro Internacional de Geografia: Tradições e Perspectivas. Universidade de São Paulo, dez. 2008.

NASCIMENTO, S. S.; VIANA DE LIMA, E. R.; SOUZA, P. L. Uso do NDVI na análise temporal da degradação da Caatinga na Sub Bacia do Alto Paraíba. Revista OKARA: Geografia em debate, João Pessoa, Paraíba, v. 8, n. 1, p. 72-93, 2014.

PONZONI, F. J.; SHIMABUKURO, E. E.; KUPLICH, T. M. Sensoriamento remoto da vegetação. 2 .ed. São Paulo: Oficina de Textos, 2012.

QUEIROZ, L. P. Angiospermas do semi-árido brasileiro. In: QUEIROZ, L. P de; RAPINI, A.; GIULIETTI A. M. (Ed.). Rumo ao amplo conhecimento da biodiversidade do semi-árido brasileiro, 2006. 
ROUSE, J. W et al. Monitoring vegetation systems in the great plains with ERTS. In: Third ERTS Symposium, Proceedings, NASA SP-351. NASA: Washington, DC, 1973. p. 309-317. (Vol. 1).

SANTANA, J. A. S.; SOUTO, J. S. Diversidade e Estrutura Fitossociológica da Caatinga na Estação Ecológica do Seridó - RN. Revista de Biologia e Ciências da Terra, v. 6. n. 2, p. 232-242, 2006.

SILVA, R. M. A. Entre dois paradigmas: combate à seca e convivência com o semiárido. Soc. Estado (Online). v. 18. n. 1-2, p. 361-385, 2003. Disponível em: <http:// dx.doi.org/10.1590/S0102-69922003000100017>. Acesso em: 10 nov. 2015.

SOUZA, B. I. Cariri Paraibano: do silêncio do lugar à desertificação. 2008. 198 f. Tese (Doutorado em Geografia) - Instituto de Geociências, Programa de PósGraduação em Geografia, Universidade Federal do Rio Grande do Sul, Porto Alegre.

SOUZA, B. I.; MENEZES, R. R.; CAMARA, A. R. Efeitos da desertificação na composição de espécies do bioma Caatinga, Paraíba/Brasil, Investigaciones Geográficas, Boletín del Instituto de Geografia, México, n. 88, p. 45-59, 2015. DOI: dx.doi.org/10.14350/rig.44092.

Lorena Andrea Cortes Ballén - Possui Graduação em Ecologia pela Pontifícia Universidade Javeriana da Colômbia, especialização em Direito Ambiental pela Universidade do Rosário da Colômbia e Mestrado em Desenvolvimento e Meio Ambiente pela Universidade Federal da Paraíba do Brasil.

Bartolomeu Israel de Souza - Possui Graduação em Geografia pela Universidade Federal da Paraíba. Mestrado em Desenvolvimento e Meio Ambiente pela mesma Universidade. Possui Doutorado em Geografia pela Universidade Federal do Rio Grande do Sul e Pós-doutorado em Biogeografia pela Universidad de Sevilla - Espanha. É professor adjunto da Universidade Federal da Paraíba.

Eduardo Rodrigues Viana de Lima - Possui Graduação em Geografia pela Universidade Federal da Paraíba. Mestrado em Sensoriamento Remoto pelo Instituto Nacional de Pesquisas Espaciais. Doutorado em Geografia pela Universidade Estadual Paulista Júlio de Mesquita Filho e Pós-Doutorado pela Universidade de Sevilla. Atualmente é professor Titular da Universidade Federal da Paraíba.

Contribuição de cada autor no desenvolvimento do artigo

Todos os autores ofereceram substanciais contribuições científicas e intelectuais ao estudo. As tarefas de concepção e design do estudo, preparação e redação do manuscrito foram realizadas pelo primeiro autor. O segundo e terceiro autor ficaram especialmente responsáveis pela revisão crítica.

Recebido para publicação em 17 de agosto de 2016 Aceito para publicação em 02 de outubro de 2016 